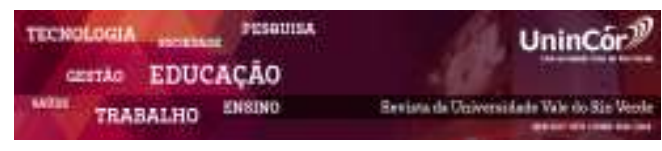

Revista da Universidade Vale do Rio Verde ISSN: 1517-0276 / EISSN: 2236-5362 v. 17| n. 1 | Ano 2019
Zionel Santana

Universidade do Vale do Rio Verde (UninCor) prof.zionel.santana@unincor.edu.br

\section{UMA GESTÃO PARTICIPATIVA EM UMA DEMOCRACIA \\ REPRESENTATIVA: AS LIMITAÇÕES DA IDEIA DE PARTICIPAÇÃO NA \\ GESTAÇÃO ESCOLAR DE HELOISA LÜCK}

\section{RESUMO}

O objetivo deste artigo é discutir à ideia de democracia e participação na gestão educacional democrática. Participação e democracia, são dois conceitos pertinentes que ainda precisar ser aclarado nos textos de Lück. Portanto, o que se entende por participação, e ao mesmo tempo, quais são as referências sobre democracia e a sua utilização na associação com a ideia de participação escolar. Deste modo, são conceitos que pressupõe esclarecimentos quando aproximamos de algumas variáveis, tais como: poder, interesse e manipulação na relação dos sujeitos envolvidos na gestão democrática escolar. Por conseguinte, esses temas são abordados a partir das contribuições de Weber, Arendt e Follett e ao mesmo tempo os contrapõem a Lück em seus textos sobre gestão educacional democrática.

Palavras-chave: Gestão Escolar; Democracia; Participação; Poder.

\section{A PARTICIPATIVE MANAGEMENT IN A REPRESENTATIVE DEMOCRACY: THE LIMITATIONS OF THE IDEA OF PARTICIPATION IN PREGNANCY HELOISA SCHOOL LÜCK}

\begin{abstract}
The purpose of this article is to discuss the idea of democracy and participation in educational management. Participation and democracy are two relevant concepts that still need be blow over in the texts of Lück. So, what is meant by participation, and at the same time, what are the references on democracy democracy and your use in association with the idea of school participation. In this manner, are concepts which requires clarification when approach of some variables, such as: power, interest and manipulation in list of subjects involved in democratic school management. Therefore, these topics are covered from contributions of Weber, Arendt and Follett and at the same time they argued the Lück in his texts on educational management.
\end{abstract}

Keywords: School Management; Democracy; Participation; Power. 


\section{INTRODUÇÂO}

O objetivo deste artigo é discutir a ideia de participação na gestão democrática, pressupõe que a ideia de democracia se estende dentro das matrizes conceituais como um tema multifacetado. A afirmação que a gestão é democrática na Lei de Diretrizes e Bases, $n^{\circ}$. 9394/96 que a gestão deverá ser democrática, não podemos supor que esta ideia já esteja solidificada na educação e muito menos na sociedade. Desta forma, o autor deste texto trabalha sobre suspeita que a gestão democrática e a participação ainda carecem de aclarações. De qual democracia está referendado na LDB ao afirmar que a gestão seja democrática? Qual é o modelo de democracia que se refere? Um modelo de democracia liberal ou republicana?

Intuitivamente, alguns autores em seus discursos partem da prerrogativa que o autor da LDB tenha como marco referencial a democracia republicana adotada no Brasil. Mas, isso não é um consenso ainda, pois há contradições na constituição dos argumentos que fundamentam a gestão democrática participativa. Isso pode ser constatado nos textos em Heloísa Lück, principalmente na sua coleção de cadernos sobre gestão educacional.

A hipótese neste trabalho é que em seus textos não há argumentos que evidencie a ideia de democracia e participação ancorados em uma matriz referencial republicana ou liberal. Portanto, o estudo se deu a partir da discussão dos elementos que constitui uma democracia e participação referente a relação de poder dos indivíduos frente ao estado e a grupos de interesses. Desta forma, o desenvolvimento da pesquisa apontou para algumas contradições do modelo republicano de democracia representativo na gestão educacional de Lück a qual se refere a participação dos indivíduos na gestão democrática. Portanto, são elementos paradoxais quando ela descreve o que se entende por participação na escola dentro de um modelo republicano de democracia representativa.

O segundo ponto abordado no texto é o conflito de interesses inerente ao grupo humano. Não há evidências nos textos de Lück da inclusão destas variáveis, poder e interesse na gestão escolar. Portanto, esta discussão sobre democracia e participação fundamenta-se a partir de três referenciais conceituais: Max Weber com a ideia de ação teleológica, onde os indivíduos deixam se guiar por interesses e fins, na tentativa de manipular o outro a partir do uso instrumental do poder: em Hannah Arendt, em que o poder é voltado para o entendimento na busca de um consenso: e, por último em Follett que concebe o poder como uma possibilidade de promover encontros entre os indivíduos para uma integração de interesses e desejos.

\section{OS ELEMENTOS CONSTITUITIVOS DE UMA GESTÃO DEMOCRÁTICA/A GESTÃo DEMOCRÁtiCA A PARTIR DA INTEGRAÇÃO DE INTERESES}

A gestão pode ser definida como compreensão de processos, pois pressupõe que a vontade e a escolha dos indivíduos sejam constituintes. Pois, os indivíduos se envolvem no processo, assumem responsabilidades e compartilham resultados. "A essência da democracia é criar. A técnica da democracia é a 
organização grupal.” (FOLLETT, 1997, p. 19). Assim, na gestão o propósito não é uma imposição de interesses, mas uma escolha consciente e responsável deles. Na visão de Follett (1997) é natural que a gestão seja democrática e participativa. Espera-se um comportamento moral dos indivíduos que de certa forma, gera obrigações e deveres. A "escolha tem um lugar no processo." (FOLLETT, 1997, p. 62).

"[...] gerenciamento é uma função integrativa total. Entre outros assuntos, responsabilidades, consenso e participação, como também aos princípios formulados para serem aplicados à situações cotidiana do ambiente de trabalho." (GRAHAM, 1997, p. 12). A gestão a partir de Follett (1997) está associada a prática democrática. Assim, o conflito é inerente ao processo democrático, ele é resultado do encontro de interesses que produz boa parte das preocupações na democracia. Idealizar uma sociedade sem conflitos seria ingênuo e romântico. "[...] o conflito é um fato da vida. Em vez de ser escondido ou ignorado deveria ser reconhecido e usado a nosso favor". (FOLLETT, 1997, p. 21). As situações conflitantes em uma organização econômica, política e educacional, eram resolvidos de duas formas segundo Follett (1997): pela dominação ou pela conciliação. Ora, a dominação representa a sobreposição de interesses. Isto é, uma parte renúncia seus interesses, enquanto a outra impõe os seus interesses. Portanto, não há a contemplação dos interesses alheios. Nem sempre a ideia hobbesiana que os mais fortes sobrepõem aos mais fracos pelo uso da força, vigora na sociedade, esse princípio natural perde a sua eficácia à medida que a dominação se dar através da instrumentalização do poder.

$O$ poder pode ser entendido a partir de três matrizes, para a compreensão das reflexões presente neste texto. A primeira, a partir da visão weberiana, a segunda na visão arendtiana e por último, a visão follettiana. Em Weber o poder pode ser compreendido como uma possibilidade de impor ao outro numa situação relacional a própria vontade. (HABERMAS, 2003). Essa compreensão weberiana tem como pano de fundo a ideia de uma ação teleológica. Isto é, uma ação racional com fim em si mesma. O exercício do poder tem na sua origem a individualidade, mesmo que grupos de indivíduos se aproximam em suas ações coletivas, ainda permanecem em sua práxis do princípio da individualidade. O objetivo da ação teleológica é o êxito em persuadir o outro, e até o ponto em satisfazer seus interesses. Ora, toda ação teleológica é dependente do comportamento do outro, desta forma, o indivíduo cria estratégias, e constitui meios de empoderamento para que possa influenciar o outro em seu comportamento para atingir os resultados esperados na contemplação de seus interesses.

Os indivíduos se utilizam de estratégias, com a clara intenção da manifestação do poder para influenciar ou manipular à vontade do outro. Essa estratégia se apoia na coação sutil que amedronta os indivíduos no espaço público, onde a manifestação acontece sorrateiramente camuflando -se de democracia -, e que se reveste de acordos voluntários e que são percebidos facilmente entre os indivíduos em defesa de seus interesses. Portanto, esse modelo de uma ação teleológica adotada pelos indivíduos na busca de 
soluções para os seus conflitos, é o que os guiam em função de seus interesses. Pois contrariamente, não estão em busca de acordos. Aparentemente, os acordos são aceitos à medida que os seus interesses são contemplados. O entendimento entre eles é sempre uma ação unilateral, o que configura o uso instrumental do poder para alcançar os seus interesses. A ação teleológica não visa um consenso entre os indivíduos, e sim uma coação sobre vontade e opiniões.

Tal prática independe do modelo de um sistema político escolhido e das suas diversas representações. O conflito é inerente a qualquer grupo humano. Se ele é inerente, teremos que nos debruçarmos sobre o seu modus operandi. Portanto, o conflito se acentua no encontro das individualidades. A vitória de um indivíduo sobre o outro depende de como cada um estará instrumentalizado de poderes. Pelo fato de que, a concepção de minorias se configura a partir desta compreensão.

A relação dos indivíduos desprovidos de empoderamento tende a ter dificuldades para garantir os seus interesses. Por conseguinte, são aqueles quem em uma sociedade desprovidos de instrumentalização de poder. A relação conflitante entre os capitalistas e os proletariados, a vitória de um sobre o outro dependerá da instrumentalização de poder que cada um possui. Basta observar o confronto dos movimentos sindicais no final do século XIX na Europa e no século XX no Brasil. Para instrumentalizar os proletariados de poderes para impor seus interesses em uma relação laboral para alcançar vantagens em relação aos capitalistas. O resultado desta prática foi a conquista dos direitos sociais e constitucionais.

\section{A PARTICIPAÇÃO DEMOCRÁTICA E O EMPODERAMENTO DOS INDIVIDUOS}

À medida que os capitalistas tomaram consciência do empoderamento do proletariado e perceberam que teriam que negociar seus interesses com os trabalhadores, passaram então a criar estratégias para remover os direitos conquistados e inclusos na constituição com o intuito de enfraquecer o empoderamento dos trabalhadores numa relação de conflito.

Isso é perceptível nos trabalhos de Karl Marx na constituição da consciência do proletariado presente no "Manifesto do partido comunista." (2005). Um dos elementos fortes da instrumentalização do poder do trabalhador na visão de Marx e Engels é a constituição de uma consciência de classe. A partir dela seria possível tomar $\mathrm{o}$ poder e reestruturar à sociedade. Gramsci a partir da interpretação da décima primeira das teses sobre Feuerbach e K. Marx entendeu que o mais importante não seria justificar as estruturas de dominação sobre o proletariado, mas transformá-las para que isso se tonasse possível, a instrumentalização do trabalhador. Gramsci desenvolveu essa ideia na “concepção dialética da história” (1981). Ora, a subordinação intelectual só foi possível a partir da solidificação de uma ideologia da dominação de classes na sociedade. Desta forma, a dominação intelectual possibilitou aos capitalistas a imposição de seus interesses pela dominação nas situações conflitantes. Portanto, os capitalistas nesse sentido estão melhor 
aparelhados do que os trabalhadores. Gramsci chama a nossa atenção que a dominação se configurou a partir do poder econômico e a sobreposição do capital sobre o trabalho.

A dominação econômica só foi possível pela política associada a uma ideologia com um aparato estatal pelos meios de comunicação. A política se configura como a instrumentalização do estado a serviço dos capitalistas. E simultaneamente, a ideologia constitui a prevalência da massificação do consenso social. A dominação depende da interiorização desta ideologia por parte do povo, é o que os impedem de construir uma visão de mundo para contrapor a ideologia burguesa. Desta forma, produz indivíduos alienados e subalternos impossibilitando a construção de sua autonomia. A ausência do senso crítico do proletariado se dar pela subordinação intelectual.

O empreendimento de Gramsci era a instrumentalização do proletariado para tomar o poder, assim ele entendia que é a forma de romper com a dominação econômica e a dominação política. $\mathrm{O}$ empoderamento do proletariado possibilitou em situações de conflito impor sua hegemonia a partir dos instrumentos de poder. Portanto, a partir dos interesses do proletariado através do empoderamento, é que seria bem-sucedido as negociações dos proletariados pela instrumentalização de poderes. Esse movimento ganha força na medida em que transcende ao proletariado com o envolvimento do estado em aparelhamento sociais para as minorias como meio desta instrumentalização.

O movimento representa a tradução de uma ideia de democracia na modernidade em uma perspectiva transformadora das defesas de interesses individuais em uma configuração coletiva.

A instrumentalização, aparelhamento, empoderamento das minorias se deu em função da conquista da vitória de seus interesses. Observa-se que esse modelo traz influências crítica-social. Entende-se que tal movimento de instrumentalização de poderes garante a individualidade como reconhecimento para resolver conflitos. Parece que Lück na força de seus argumentos justifica uma gestão democrática que supere os conflitos dentro do modelo de dominação. "[...] Essa participação dá às pessoas a oportunidade de controlarem $\mathrm{o}$ próprio trabalho, assumirem autoria sobre o mesmo e sentirem-se responsável por seus resultados - portanto, construindo e conquistando sua autonomia." (LÜCK, 2013, p. 23).

“A participação [...] é fácil de observar que ele não passa com muita frequência de simples verbalização de opiniões [...], que corresponda também ao compartilhamento de poder e de responsabilidade por sua realização." (LÜCK, 2013, p. 40). O simples fato de professores, alunos e pais se reunirem para colocarem em prática a gestão participativa na escola, evidencia uma alienação dos participantes sobre a relação de interesses que está em jogo. A questão a saber é; quem está melhor instrumentalizado de poderes? Na relação entre professores, alunos e pais? Dependerá da instrumentalização de poderes de cada um. Ao nos referimos à escola pública, perceberemos que os professores em relação aos alunos e aos pais terão muito mais chances de impor seus interesses, pois estão mais instrumentalizados de 
poderes de saber. Mas quando os comparamos com o estado na sua representação político ideológica na representação do diretor da escola, dos secretários da educação. Os professores, os alunos e os pais estão menos instrumentalizados de poderes nessa situação de negociação de interesses. Essa relação se agrava mais ainda, quando aproximamos os professores alunos e pais em relação à instrumentalização de poder do Estado na dominação ideológica.

$$
\text { O estado está amplamente }
$$

instrumentalizado de poderes em uma relação de conflito contra os professores, os alunos e os pais, pois sempre sobrepõe os seus interesses ou de grupos nesta relação. $O$ estado é um instrumento de dominação a serviço de grupos de interesses (Marx), essa constatação de Marx independe do modelo político que se escolhe.

Se o conflito aparece nas relações entre os indivíduos em seus grupos sociais, cabe indagar a quem o estado instrumentalizou de poderes para a imposição de interesses. Ora, se o estado instrumentalizasse os indivíduos, então teríamos em uma relação de conflito a vitória dos indivíduos sobre os grupos e sobre o mercado. Portanto, os indivíduos estariam melhor aparelhados em uma negociação de conflito e não abririam mão de seus interesses $\mathrm{e}$ conseguiriam a manutenção de seus direitos. Ao adotar um modelo de democracia representativa, a instrumentalização dos indivíduos é reduzida à vontade do estado e que não garante nem a manutenção de seus interesses. Em uma democracia participativa os indivíduos sempre desconfiam das boas intenções do estado, e por isso, o matem sempre sob vigília.

\section{UMA GESTÃO DEMOCRÁTICA PARTICIPATIVA EM UM MODELO DE DEOCRACIA REPRESENTATIVA}

Em uma democracia participativa a constituição da instrumentalização de poderes dos indivíduos depende muito mais dos movimentos da sociedade civil organizada do que o próprio estado. Diferentemente, em um modelo de democracia representativa, em que os indivíduos confiam sempre nas boas intenções do estado, e não o colocam sob suspeita. Consequentemente, dependem do estado para dispor da instrumentalização dos seus poderes e não de uma sociedade organizada. Eles não percebem os interesses do estado e dos grupos aparelhados que com facilidade exclui os interesses dos indivíduos nas relações conflitantes. Isso só é possível, segundo Gramsci (1981) pela subordinação intelectual a partir da solidificação pela reprodução do poder dos grupos majoritários. Fica evidente o jogo nessa situação em que os grupos com melhor instrumentalização de poder econômico e de poder político que se servem do estado para as garantias da sobreposição dos seus interesses em relação aos indivíduos e a sociedade.

Neste modelo, de democracia representativa os indivíduos vivem a ilusão que o estado estará a seu favor nas relações conflitantes que afetam os seus interesses. Isso é resultado da interiorização ideológica pelos indivíduos em um processo de alienação. Por isso que é perceptível a derrota dos indivíduos em situações de conflitos contra o estado e as organizações econômicas, jurídicas, políticas e até mesmo organizações criminosas quando 
estão mais instrumentalizadas do que a própria sociedade impõe seus interesses.

"Participação, portanto, não é discussão nem mera expressão de aval a decisões." (LÜCK, 2013, p. 24). A gestão participativa de Lück representa mais uma gestão representativa, assim não leva em consideração as contradições dos dois modelos de representação de poder. As propostas na educação contradizem o que os indivíduos e a sociedade buscam como inspiração de seus interesses. A ideia de participação está longe de entender que o modelo de democracia que se adotou no Brasil, depende muito mais de uma instrumentalização do estado e dos grupos de interesses do que dos indivíduos desprovidos de aparelhamento para resolverem conflitos. Pois, estão sempre em desvantagem instrumental. A proposta de Lück não leva em consideração esses elementos pertinentes à gestão participativa na escola.

A leitura de Follett (1997) sobre a participação, pressupõe que os interesses dos indivíduos sejam contemplados. A isso ela se refere a terceira forma de resolver os conflitos, a integração. "[...], é possível superar o exercício do poder individual e de preferência empregado nas escolas e promover a construção do poder da competência, [...]." (LÜCK, 2013, p. 23). Diferentemente de Lück, as compreensões de Follett são que em uma relação de conflito se os seus interesses também não forem contemplados, os indivíduos desenvolvem um sentimento de frustração na constituição de projetos coletivos, perdem à motivação política tão essencial para o exercício da cidadania e a constituição da autonomia. Por isso que é comum observar nas diversas discursões de professores apontado por Lück (2013, p. 33):

\begin{abstract}
Assim manifestou uma professora a respeito: em nossa escola, o momento de participação são para resolver problemas que a diretora ou a Secretaria de Educação desejam resolver. Em geral sabemos o que querem, mas fazem reunião para convencer a gente ou para identificar resistências. Mas ouvimos que falamos e no fim todo mundo tem a impressão de que a decisão foi coletiva
\end{abstract}

A segunda concepção de poder neste texto, parte da compreensão de Hannah Arendt que o entende como uma capacidade de colocarse de acordo a partir de uma comunicação sem a coação. É o que se espera de uma negociação que as ações em comunicação, não sejam de coações. Ação instrumentalizada de poder se configura pela força, pela violência e a repressão. Portanto, os indivíduos atuam racionalmente voltados para obterem seus resultados, isto é, exclusivamente para os seus interesses ou para o êxito de suas ações a serem bem-sucedidos, os quais dispõem de meios e criam estratégias para também influenciar os indivíduos na sua tomada de suas decisões, por meio de persuasão, ou, manipulações sutis que alteram opiniões e decisões.

A participação efetiva na escola pressupõe que os professores, coletivamente organizados, discutam e analisem a problemática pedagógica que vivenciam em interação com a organização escolar 
e que, a partir dessa análise, determinem caminhos para superar as dificuldades que julgarem mais carentes de atenção e assumam compromisso com a promoção de transformação nas práticas escolares. (LUCK, 2013, p. 34).

Diferentemente de Lück que entende que na gestão pedagógica democrática os conflitos devem ser superados a partir de uma negociação. Isto é, os professores precisam renunciar parte de seus interesses para alcançarem um fim que responsavelmente assumam o erro. Mas em Follett (1997), a gestão é um processo do encontro entre os indivíduos, objetos em um ambiente aberto, sistêmico em constante mutação. A manipulação da opinião e das decisões dos indivíduos sofrem influências e refluências o tempo todo. Isto é, a imposição de uma vontade aos indivíduos pode vir de ações externas e internas, inclusive sistêmicas. Os interesses não devem ser superados, mas sim integrados.

$\mathrm{Na}$ negociação pressupõe um grau de conscientização, mesmo que seja pequena, e mesmo que movida por interesses individuais. Desta forma, o acordo voluntário é uma aproximação de interesses comuns, que as partes terão que ceder para que os sujeitos saiam da perspectiva de expectadores para participantes, ou da passividade para interessados.

Esta compreensão em Arendt tenta romper com a ação teleológica weberiana, pois para ela, os indivíduos se deixam guiar a partir de interesses ou ações para bons resultados. $\mathrm{Na}$ ação teleológica não há uma busca de uma negociação. Só admitem processos de entendimento à medida que os interessados consideram funcionalmente necessário para seus fins. (HABERMAS, 2003). Desta forma, o posicionamento de Arendt nos ajuda a compreender que na participação esta inerente a uma relação de poder, de instrumentalização de poderes e que a participação são ações dos envolvidos movidos por interesses. Portanto, o poder surge da capacidade que os indivíduos possuem, não se limitam somente para a performance de seus papeies. O poder vai além dessa concepção limitante, ele serve para que os indivíduos também se conectem conjuntamente.

“[...], participação como engajamento implica envolver-se dinamicamente nos processos sociais e assumir responsabilidade por agir com empenho, competência e dedicação visando promover os resultados propostos e desejados.” (LUCK, 2013, p. 47). Gestão democrática, participativa na escola pressupõe o poder como um fenômeno a ser observado nas relações entre os envolvidos. É inerente à educação em seu processo complexo, o poder. $\mathrm{O}$ estudo sobre o poder poderá nos levar a perceber o quanto os envolvidos estão instrumentalizados para impor a sua vontade e manipular opiniões e decisões e usar do outro para atingir resultados. Portanto, na integração supõe na sua origem a ideia de comunidade como afirma Follett (1997) voltada para o entendimento.

\section{INSTRUMENTALIZAÇÃO DO PODER DOS INDIVIDUOS NA GESTÃO PATICIPATIVA}

$\mathrm{O}$ poder se configura como uma propriedade de um sistema que se movimenta 
nos encontros entre as partes, que interagem entre si, indivíduos, objetos e ambiente. A interação entre os indivíduos carrega já na sua origem um princípio de racionalidade kantiana, pois os indivíduos são racionais dotados de boa vontade e desejam resolver os seus problemas. Por isso, as suas escolhas tendem ao bem e o bem é racional-, a racionalidade segue princípios universais válidos. De agora, espera-se que os indivíduos tenham a capacidade moral e social em se mobilizarem com os seus recursos disponíveis para fins coletivos em uma integração. A concepção de Arendt é que a ação não instrumentalizada dos indivíduos podem avançar além do egoísmo individual.

Na compreensão de Follett (1997, p. 76), tanto a dominação como a negociação conduzem os grupos humanos a um processo de degeneração das relações e podendo atingir estágios patológicos. Observe-se nas assembleias e nos congressos, a instrumentalização de partidos políticos na luta pelos seus interesses que sobrepõe até mesmo os interesses de todo um povo, utilizando -se de todos os meios de aparelhamento para impor, manipular a opinião pública de que os seus interesses são os melhores para o bem do povo.

A mesma prática podemos encontrar nas organizações de forma geral, o que não é diferente em uma organização educacional que grupos de interesses que se apoderam da educação a partir da instrumentalização de poderes. É notório a percepção de projetos diferentes para as soluções de conflitos na sociedade que são aprovados nas assembleias à medida que contemplam os interesses de grupos ou até de partidos que são indiferentes aos interesses do povo. Isso, acontece porque o povo está desinstrumentalizado para impor os seus interesses. A democracia representativa possibilita a jardinagem para o desenvolvimento dessa cultura.

"[...] o gerenciamento não restringe às empresas, mas é função genérica de todas as organizações, até mesmo governamentais." (GRAHAM, 1997, p. 6). Follett (1997) propõe na gestão democrática a integração como superação da dominação e da negociação. Isto é, em uma perspectiva participativa e não representativa. A integração é quando os desejos se integram. Talvez, o desejo aqui para Follett seja diferente de Weber e Arendt na ideia de interesse. Para ela, o desejo vai além dos interesses. Pois, não seria possível uma integração baseada nos interesses. Isso é perceptível na dominação e na negociação. Assim, a motivação é positiva para encontrar uma solução para os conflitos. Pressupõe um respeito, uma delimitação de espaço e o abandono da prática tradicional do sacrifício dos indivíduos em detrimento dos fins.

Em uma democracia participativa não há perdedores, há sim integração de desejos. O mesmo se aplica a uma organização econômica e educacional. Não há projetos educacionais vencedores ou rejeitados. Há que se repensar essa prática presente nas soluções dos conflitos, que entende que a construção da nossa educação passa por projetos que devem vencer para serem implementados. Isso não faz mais sentido.

A integração necessariamente envolve todos. Por isso que, cria algo sempre novo. Ao propor um projeto em uma assembleia, ou em uma escola, ao ser aprovado, ele não poder ser o 
mesmo da sua origem. É essa compreensão que Follett nos apresenta na gestão democrática que integra os desejos de todos, o resultado é algo novo e criativo. Tal discussão em Follett, nos chama atenção para a ideia embrionária da inclusão da diversidade na elaboração de projetos para a educação e para a sociedade. A gestão democrática abre espaço para a restituição de desejos. A integração não elimina os conflitos, pois eles surgiram em um outro momento. Pois, os indivíduos renunciaram na negociação parte de seus desejos é o que faz com que não seja completa a ação. (FOLLETT, 1997). Assim, a negociação desenvolve o sentido de frustração e insatisfação entre os indivíduos. Como já vimos na dominação e na negociação. Nelas os indivíduos abrem mão de seus interesses na medida em que estão menos instrumentalizados de poderes. Essa atitude faz com que os indivíduos em algum momento tentaram recuperar a totalidade de seus desejos. Os indivíduos sempre querem reabrir os conflitos de onde pararam para depois modificá-los e incluir os seus desejos.

Em uma assembleia e comum essa prática de legitimação de interesses, em que os partidos percebem que os seus interesses não foram contemplados em uma aprovação de um projeto. Eles tentaram reunir forças, ou ampliarem o seu empoderamento para que possam reabrir a discussão do projeto em um momento oportuno, para incluir os seus interesses. E a isso, chamamos de participação democrática. Essa é a ideia subliminar que desenvolvemos de democracia.

Na negociação o conflito sempre virá à tona novamente, e essa prática impossibilita o avanço dos grupos, da sociedade de forma geral. Essa prática também é comum na educação. Pois ela é feita de projetos que são aprovados ou rejeitados. Observem a dinâmica dos projetos educacionais, normalmente estão vinculados a perspectivas ideológica, muito claras no Brasil. De um lado, a direita que busca em um fundo neoliberal, de uma educação prática voltada para o mercado, não dando ênfase a conteúdos reflexivos e humanísticos. E de outro lado, os de fundamentação de esquerda que querem uma educação voltada para uma formação mais humanista com peso na consciência social e sem um direcionamento para o mercado. E aqueles que se definem a partir de temas na educação e não apresentam projetos consistentes.

O projeto de educação oscila entre duas formas, a dominação e a negociação, dependendo do período a dominação tem mais força para impor a todos um projeto de educação de forma diretiva, uma prática muito comum desde o período da administração escolar na década de 70. A negociação é uma das suas estratégias para convencer a sociedade a renunciar partes de seus interesses educacionais na implementação do projeto educacional Esse dois modelos de projetos de educação não possibilitaram o avanço da educação no Brasil, basta ver às últimas pesquisa que demonstraram o fracasso deste tipo de escolha. A gestão Educacional fundada na perspectiva follettiana poderá responder melhor a essas questões.

\section{CONCLUSÃO}

Em uma gestão democrática, os interesses dos indivíduos é parte constituinte do 
processo. A questão é: como a gestão democrática integra às diferenças nas discussões conflitantes na escola? Para essa questão, a pesquisa apontou para três possiblidades: a primeira, se revolve de forma diretiva, ainda naquela visão do modelo tradicional de administrar, pela dominação. Portanto, a imposição e o uso da autoridade, ou, da força e até mesmo a coerção. Esse comportamento era comum nas empresas em que o diretor decidia e fazia cumprir as suas decisões. A segunda possibilidade para resolver os conflitos passava pela negociação, os indivíduos criam estratégias para influenciar o outro, ou manipulando-o para atingir os seus fins. Isto é, os acordos voluntários aconteciam à medida que os interesses eram comtemplados. Portanto, o poder como uma capacidade de cercar o outro a partir de uma comunicação não cooperativa. A integração a partir de Follett tem um alcance de melhor envergadura quando nos referimos a gestão participativa. A integração leva em consideração os elementos importantes nas relações conflitantes. Follett pressupõe que em uma democracia às diferenças são constituintes e devem ser gerenciados a partir de uma perspectiva criativa. Na gestão democrática os conflitos são integrados para se chegar às respostas novas e que os indivíduos se integram cada vez mais a partir dos encontros. Portanto, a gestão democrática Follettiana se apresenta possibilidade de como devemos reavaliar os nossos interesses e desejos sempre, pois, em um ambiente aberto, eles mudam o tempo todo. Daí, a proposta da autora que eles não administrados mais sim gerenciados. E por último, Follett nos apresenta a integração como possibilidade para resolver os conflitos de interesses. A sua proposta é ir além dos interesses egoístas e migrar para a compreensão de que os desejos dos indivíduos têm muito mais a contribuir na gestão democrática, pois eles são capazes de a partir dos seus desejos estabelecerem relações cooperativas visando a constituição da comunidade de juris consórcio.

\section{REFERÊNCIAS}

GRAHAM, Pauline. (org). Mary Parker Follett: profeta do gerenciamento. Tradução: Eliana Chiochet de Abreu Lima. Rio de Janeiro: Qualitymark, 1997.

HABERMAS, Jürgen. Perfiles filosóficos-políticos. Trad.Manuel Jiménez Redonto. Taurus: Madrid, 2003.

LÜCK, Heloísa. et al. A escola participativa: o trabalho do gestor. 5. ed. Rio de janeiro: DP\&A, 2001.

LÜCK, Heloísa. Gestão educacional: uma questão paradigmática. 2. ed. Petrópolis: Vozes, 2006. Vol. I. . Concepções e processos

democráticos de gestão educacional. 9. ed. Petrópolis: Vozes, 2013. Vol. II.

. A gestão participativa na escola. 11 . ed. Petrópolis: Vozes, 2013. Vol. III.

. Liderança em gestão escolar. 9. ed. Petrópolis: Vozes, 2014. Vol. IV.

. Gestão da cultura e do clima

organizacional da escola. 2. ed. Petrópolis: Vozes, 2011. Vol. V.

. Perspectivas da avaliação

institucional da escola. Petrópolis: Vozes, 2012. Vol. VI.

. Avaliação e monitoramento do

trabalho educacional. 2. ed. Petrópolis: Vozes, 2013. Vol. VII.

Gestão do processo de aprendizagem pelo professor. Petrópolis: Vozes, 2014. Vol. III.

. Dimensões da gestão escolar e suas

competências. Curitiba: Positivo, 2009. Disponível em:

<file:///D:/Gestão\%20educacional/dimensoes_livro.pd f>. Acesso em: 15 jan. 2019. 


\section{Zionel Santana}

Professor de Ciências Administrativas, Econômicas,

Filosofia e Ciências Políticas. Integra o Corpo Docente do

Programa de Pós-Graduação Stricto Sensu em Gestão,

Ensino e Planejamento da Universidade do Vale do Rio

Verde. E-mail prof.zionel.santana@unincor.edu.br 